\title{
PENERAPAN M-BANKING DALAM MENINGKATKAN JASA DAN LAYANAN PERBANKAN DI PT. BANK PEMBANGUNAN DAERAH SUMATERA BARAT CABANG SITEBA
}

\author{
Annisaa' Putri Riayu, Romi Susanto \\ Akademi Keuangan dan Perbankan "Pembangunan" Padang \\ annisaputririayu29@gmail.com
}

\begin{abstract}
Purpose of this study is to see the implementation of M-banking in improving services and banking services and obstacles in implementation M-banking on PT. Pembangunan Deerah Sumatera Barat Branch Padang. This study, using qualitative data analysis as a method of research that explains the Descriptive on the Application of M-Banking to Improve Services and Banking Services at PT. Pembangunan Deerah Sumatera Barat Branch Padang. The method of analysis in terms of practices that need to be applied, so that can know the extent of implementation. The results of this study indicate that the application of Nagari MBanking is easy in conducting financial and non-financial transactions, so it does not need to be done directly to a bank office or even to an ATM
\end{abstract}

Keywords: Application, Services, M-Banking

\section{PENDAHULUAN}

PT. Bank Pembangunan Daerah Sumatera Barat Cabang Siteba merupakan salah satu bank pembangunan daerah yang memberikan pelayanan bagi setiap nasabahnya. dalam upaya peningkatan layanan, pada tahun 2019 PT. Bank Pembangunan Derah Sumatera Barat Cabang Siteba mengeluarkan suatu layanan yang dapat mempermudah nasabahnya dalam melakukan transaksi yaitu Nagari Mobile Banking, Nagari mobile banking merupakan jasa layanan transaksi keuangan perbankan yang dapat diakses dengan menggunakan handphone seluler berbasis internet, nagari mobile banking dapat diakses kapanpun dan dimanapun, sehingga nasabah tidak memiliki batas atau hambatan dalam melakukan transaksi. Nagari Mobile banking menyediakan fitur yang cukup beragam, salah satunya yaitu fitur transfer, nasabah dapat melakukan transfer dana baik kesesama nasabah bank Nagari maupun ke nasabah bank lainya dan juga nasabah bank Nagari juga dapat melakukan pembayaran dan pembelian, seperti pembelian token listrik, pembayaran PDAM dan fintect lainya. Dengan adanya mobile banking ini diharapkan nasabah terus dapat meningkatkan kepuasannya dalam menggunakan bank Nagari sebagai bank utama dalam melakukan transaksi keuangan maupun non keuangan.

Dalam prakteknya, dengan adanya kemudahan pelayanan yang diberikan mobile banking, tidak menjamin selalu memberikan keamanan yang tinggi bagi setiap 
nasabahnya dalam menjaga keamanan dana atau aset yang dimiliki nasabah. Mobile banking mewajibkan setiap nasabahnya dalam menjaga keamanan dananya untuk menggunakan kode akses dan password, hanya nasabah dan orang yang memiliki izin akses yang dapat mengakses mobile banking nasabah, akan tetapi dengan tingginya tingkat keamanan mobile banking ini, masih adanya kasus penipuan atau kehilangan aset yang dialami oleh nasabah.

Akhir-akhir ini maraknya terjadi penipuan yang dialami oleh nasabah pengguna Nagari mobile banking. Penulis melakukan wawancara kepada salah satu nasabah Nagari mobile banking yang mengalami penipuan, nasabah yang mengalami penipuan karena lupa menuntup aplikasi nagari mobile banking dalam menggunakan aplikasi VPN, hal ini menyebabkan kemudahan para hacker dalam melakukan penyadapan data nasabah, sehingga nasabah mengalami kerugian puluhan juta rupiah, selain itu, kasus lain yang dialami nasabah dalam menggunakan nagari mobile banking yaitu kurangnya pengetahuan nasabah dalam menggunakan aplikasi nagari mobile banking, seperti yang dialami oleh Nurjanah, Nurjanah mengalami kerugian karena kurangnya pengetahuan dalam menggunakan nagari mobile banking, ketika Nurjanah akan membayar pesanan salah satu market place dengan menggunakan virtual account, nurjanah melakukan pengiriman dengan jumlah yang berbeda, sehingga Nurjanah mengalami kerugian ratusan ribu rupiah.

Dari kasus-kasus penipuan dan kurangnya pengetahuan nasabah dalam menggunakan Nagari mobile banking ini, diduga masih kurangnya tingkat keamanan aplikasi Nagari mobile banking dalam melindungi data nasabah dan penggunaan kode OTP sebagai kode izin akses dalam melakukan setiap transaksi. Untuk itu PT. Bank Pembangunan Daerah Sumatera Barat Cabang Siteba agar dapat meningkatkan kualitas nagari mobile banking dan inovasi pada setiap jasa layanan yang disediakan bagi setiap nasabahnya sehingga nasabah tidak mengalami penipuan dan kekeliruan dalam melakukan transaksi.

Tindakan penipuan dalam perbankan seperti ini adalah salah satu bentuk ancaman atau resiko yang akan dialami oleh pengguna mobile banking yang tidak memiliki pengetahuan yang cukup dalam menggunakan aplikasi mobile banking. Agar nasabah dapat menghindari hal tersebut, perusahaan seharusnya memberikan edukasi yang benar dan baik dalam menggunakan mobile banking untuk menghindari terjadinya penipuan dan kasus penyalahgunaan m-banking lainya. Perlunya peningkatan system keamanan yang harus disediakan oleh penyedia, agar nasabah dapat menggunakan aplikasi dengan aman tanpa memikirkan terjadinya penipuan ataupun pembobolan data nasabah.

Berdasarkan penjelasan diatas, untuk meningkatkan kepercayaan nasabah pada jasa perbankan dan pemahaman nasabah dalam penggunaan fasilitas M-Banking maka sangat penting bagi saya untuk mengadakan penelitian dengan judul "Penerapan M-Banking Dalam Meningkatkan Jasa dan Layanan Perbankan di PT. Bank Pembangunan Daerah Sumatera Barat Cabang Siteba". 


\section{Tinjauan Pustaka \\ Perbankan}

Bank memiliki peran sangat penting dalam mendukung mobilitas masyarakat, bank tidak hanya sebuah lembaga tempat simpan dan pinjam saja, tetapi sudah menjadi lembaga besar yang mampu mengcover sumua aktifitas keuangan masyarakat. Bank sebagai suatu lembaga memberikan jaminan keaman yang cukup tinggi dalam melakukan transaksi keuangan. Dengan demkian, semakin tingginya ketergantungan masyarakat akan fungsi bank dan lembaga keuangan lainya, hal ini menandakan bahwa bank sudah menjadi suatu kebutuhan dalam masyarakat (Kasmir, 2010:1).

1. Bank

Bank didefinisikan oleh Undang - Undang Nomor 10 Tahun 1998 tentang perubahan UU Nomor 7 Tahun 1992 tentang Perbankan sebagai "badan usaha yang menghimpun dana dari masyarakat dalam bentuk simpanan dan menyalurkannya kepada masyarakat dalam bentuk kredit dan atau bentukbentuk lainnya :

a. Bank Umum

Bank umum didefinisikan sebagai bank yang melaksanakan kegiatan usaha secara konvensional atau berdasarkan prinsip syariah yang dalam kegiatannya memberikan jasa dalam lalu-lintas pembayaran. Kegiatan usaha yang dapat dilakukan oleh bank umum adalah :

1. Menghimpun dana dari masyarakat dalam bentuk simpanan berupa giro, deposito berjangka, sertifikat deposito, tabungan atau bentuk lainnya.

2. Memberikan kredit, menerbitkan surat pengakuan utang, membeli, menjual atau menjamin atas risiko sendiri maupun untuk kepentingan dan atas perintah nasabahnya.

3. Bertindak sebagai pendiri dana pensiun dan pengurus dana pensiun sesuai dengan ketentuan dalam peraturan perundang-undangan dana pensiun yang berlaku.

b. Bank Perkreditan rakyat

Bank Perkreditan Rakyat didefinisikan sebagai lembaga keuangan yang dimiliki oleh darah atau perseroan yang fungsi utamanya memberikan layanan kredit atau pinjaman kepada nasabahnya atau kreditur. Bank ini lebih fokus pada pendanaan nasabah untuk sector produktif, seperti usaha dan kegiatan produktif lainya.. Kegiatan usaha yang dapat dilakukan oleh Bank Perkreditan Rakyat secara lengkap adalah:

1. Menghimpun dana dari masyarakat dalam bentuk simpanan berupa deposito berjangka, tabungan, atau bentuk lainnya yang dipersamakan dengan itu.

2. Memberikan kredit

3. Menyediakan pembiayaan dan penempatan dana berdasarkan prinsip syariah sesuai dengan ketentuan yang ditetapkan oleh Bank Indonesia. 


\section{Pengertian Jasa Perbankan}

Dalam Susanto (2019), selain menjalankan fungsinya sebagai intermediares (penghubung) antara pihak yang membutuhkan dana (deficit unit) dengan pihak yang kelebihan dana (surplus unit), bank dapat pula melakukan berbagai pelayanan jasa perbankan.

Jasa merupakan suatu bentuk pelayanan yang secara hakikatnya tidak dapat terlihat oleh pemberi jasa maupun sang penerima jasa. Jasa dapat diklasifikasikan dalam bentuk bantuan yang dapat mempermudah sang pengguna jasa tersebut.. Menurut Nasution (2016) jasa merupakan semua aktivitas ekonomi yang hasilnya tidak merupakan produk dalam bentuk fisik atau konstruksi, yang biasanya dikonsumsi pada saat yang sama dengan waktu yang dihasilkan dan diberikan nilai tambah atau pemecahan atas masalah yang dihadapi konsumen.

Menurut Jasfar (2014) menerangkan bahwasanya jasa itu adalah setiap tindakan atau aktivitas dalam bentuk pelayanan yang tidak memiliki bentuk atau wujud, para pengguna jasa dapat merasakan pelayanan atas jasa yang diberikan. Dalam dunia perbankan sendiri jasa yang dapat diberikan yaitu suatu bentuk pelayanan yang dapat mempermudah masyarakat dalam melaukan transaksi keuangan maupun transaksi non-keuangan. Pada dasarnya bank memiliki tiga fungsi yang utama, yaitu menghimpun dana dari nasabah, mendistribusikan dana dalam bentuk kredit dan pelayanan dalam bentuk jasa transaksi keuangan..

Menurut Undang-Undang No. 7 Tahun 1992 tentang perbankan sebagaimana telah diubah dengan Undang-Undang No. 10 Tahun 1998, pengertian bank adalah sebagai berikut bank adalah badan usaha yang menghimpun dana dari masyarakat dalam bentuk simpanan dan menyalurkannya kepada masyarakat dalam bentuk kredit dan atau bentuk kredit lainnya dalam rangka meningkatkan taraf hidup rakyat banyak.

Dan berdasarkan SK Menteri Keuangan RI Nomor 792 tahun 1990 bank merupakan suatu badan yang kegiatannya di bidang keuangan melakukan penghimpunan dan penyaluran dana kepada masyarakat terutama guna membiayai investasi perusahaan

\section{Pengertian Mobile Banking}

Menurut Riswandi (2015:83) M-Banking merupakan suatu fasilitas yang disediakan oleh penyedia jasa atau bank yang dapat mempermudah masyarakat dalam melakukan transaksi keuangan maupun non keuangan dengan menggunakan perangkat atau handphone yang berbasis internet. Melalui handphone nasabah atau masyarakat dapat mengakses transaksi perbankan dimanapun dan kapanpun tanpa harus mengunjungi kantor bank atau ATM. M-banking sangat membantu masyarakat yang memiliki mobilitas tinggi, tetapi tidak memiliki waktu yang cukup untuk mengunjungi kantor bank, dengan adanya M-banking mempermudah masyarakat dalam melakukan transaksi, seperti transfer dana, pembayaran cicilan, pembayaran listrik, pembelian pulsa dan transaksi keuangan dan non keuangan lainya. M-Banking merupakan suatu layanan perbankan yang dapat diakses langsung oleh nasabah melalui handphone dengan menggunakan menu yang sudah tersedia di Subcriber 
Identity Module Card (SIM Card) atau biasa dikenal dengan Menu Layanan Data atau SIM Toolkit.

\section{Jenis-Jenis Transaksi M-Banking}

Menurut Riswandi (2015:85), saat ini transaksi M-Banking sudah dapat melakukan banyak hal, tetapi masih akan dapat berkembang lebih jauh lagi di waktu mendatang. Transaksi yang saat ini dapat dilakukan antara lain:

1. Tranfer dana atau pemindahan dana

Melakukan transfer atau pemindahan dana kepada rekening sesama bank, atau ke rekening bank lainya

2. Informasi
a. Saldo
b. Transaksi
c. Lainya

3. Pembayaran
a. Listrik
b. Handphone berbagai operator
c. Iuran TV kabel
d. Pajak Bumi dan Bangunan
e. Kartu Kredit
f. Lainya

4. Pembelian

a. Pulsa telepon/handphone berbagai operator

b. Tiket pesawat

c. Pulsa PLN prabayar

d. Lainya

Munculnya M-Banking itu sendiri tidak hanya berhubungan dengan bank saja, tetapi juga bekerja sama dengan operator selular. Sehingga dapat dilihat bahwa keberadaan M-Banking memberikan keuntungan kepada semua kalangan, seperti bank, operator selular dan nasabah bank pengguna $M$-Banking.

\section{Manfaat M-Banking}

Menurut Riswandi (2015:87), M-Banking memiliki manfaat yang cukup banyak bagi penggunanya, yaitu sebagai berikut:

1. Kemudahan Layanan

Layanan M-Banking memiliki kelebihan dibandingkan internet banking karena relatif mudah dalam mendapatkan konektivitas, sedangkan untuk internet banking tidak semua tempat ada jaringan internet. Hal ini memudahkan nasabah dalam melakukan transaksi keuangan sehingga menghemat banyak waktu.

2. Keragaman Fitur

Fitur yang sederhana membuat mobile banking melalui ponsel sangat mudah untuk dimengerti. Semua isntruksi diberikan secara mudah dan rinci sehingga 
efektif dari segi biaya. Selain itu fasilitas mobile banking mempunyai biaya yang rendah dibandingkan online banking.

3. Keamanan

Dari sisi keamanan mobile banking bisa mengurangi resiko penipuan karena nasabah akan mendapatkan SMS ketika terdapat aktivitas pada rekening nasabah baik setoran, penarikan uang, atau transfer antar rekening.

4. Biaya

Bank juga merasa untung dengan layanan Mobile banking karena bisa mengurangi biaya dari tele-banking dan lebih ekonomis, selain itu fasilitas tambahan ini bisa mempermudah konsumen melakukan transaksi, sehingga bank dapat meningkatkan kepuasan nasabah mereka. Selain itu bank juga merasa lebih dekat dan dapat menjangkau nasabah mereka dengan mobile banking.

5. Produk Layanan

Produk bank juga bisa dipromosikan dengan mudah melalui iklan layanan mobile banking seperti kartu kredit, pinjaman, dan lainnya pada kelompok nasabah tertentu. Selain promosi produk, berbagai layanan bank yang bisa diakses melalui mobile banking meliputi informasi pembayaran rekening, informasi jumlah tabungan, histori transaksi, fasilitas pengiriman uang, dan lainsebagainya dapat diakses langsung melalui handphone nasabah.

\section{METODE ANALISIS DATA}

Dalam menganalisa data, penulis menggunakan analisis data Kualitatif sebagai metode penelitian yang menjelaskan secara Deskriptif mengenai Penerapan MBanking Dalam Meningkatkan Jasa dan Layanan Perbankan Di PT. Bank Pembangunan Daerah Sumatera Barat Cabang Siteba. Metode analisis ditinjau dari dua praktek yang perlu diterapkan, sehingga dapat diketahui sejauh mana pelaksanaannya. Apakah perbedaan yang timbul menyangkut prinsip dasar konsep itu sendiri, pertanyaan itu akan terjawab selanjutnya dari hasil analisa itu digunakan sebagai dasar pengambilan kesimpulan dan saran.

\section{HASIL DAN PEMBAHASAN}

Penerapan M-Banking Dalam Meningkatkan Jasa dan Layanan PT. Bank Pembangunan Daerah Sumatera Barat Cabang Siteba

Dalam rangka PT. Bank Pembangunan Daerah Sumatera Barat Cabang Siteba merupakan produk keuangan dalam bentuk perbankan yang dimiliki oleh pemerintah Sumatera barat. Dengan semakin meningkatnya persaingan perbankan, untuk itu PT. Bank Pembangunan Daerah Sumatera Barat Cabang Siteba juga melakukan inovasi untuk meningkatkan pelayanan kepada para nasabahnya dalam bentuk M-Banking. Fitur ini dapat membantu dalam memudahkan nasabah bertransaksi baik transaksi keuangan maupun transaksi non keuangan, dengan adanya fitur M-Banking ini diharapkan nasabah lebih mobile dalam bertransasi tanpa harus datang kekantor 
maupun gerai ATM. Berikut ini upaya peningkatan layanan melalui fitur-fitur Nagari M-Banking

1. Nagari Info

Dengan adanya fitur ini PT. Bank Pembangunan Daerah Sumatera Barat Cabang Siteba memberikan pelayanan dan kemudahan bagi setiap nasabahnya untuk mengetahui jumlah saldo yang ada dalam rekening nasabah, sehingga nasabah dapat melakukan akses dengan mudah dan cepat untuk mengetahui info saldo rekening dimanapun dan kapanpun. Selain itu nasabah juga dapat mengetahui informasi-informasi atas transaksi yang telah dilakukan nasabah.

2. Nagari QR

Nagari QR merupakan produk atau fitur terbaru yang baru diluncurkan oleh PT. Bank Pembangunan Daerah Sumatera Barat awal tahun 2020, fitur ini diharapkan dapat mempermudah nasabah dalam melakukan pembayaran dan transfer melalui scan kode batang sehingga transaksi pembayaran dan transfer dapat dilakukan dengan cepat dan aman. Selain ini PT. Bank Pembangunan Daerah Sumatera Barat Cabang Siteba juga telah bekerja sama dengan berbagai macam fintech dan marcant guna memperluan jangkauan transaksi seperti pembayaran adira finance dan lainya. Dengan adanya fitur ini diharapkan nasabah terus meningkatkan jumlah transaksinya dengan mengunakan Nagari M-Banking.

3. Nagari Transfer

PT. Bank Pembangunan Daerah Sumatera Barat Cabang Siteba terus berupaya meningkatkan pelayanan kepada setiap nasabahnya, tidak terkecuali dalam mempermudah nasabah dalam melakukan transfer, baik transfer kepada sesama rekening Nagari maupun rekening bank lainya, dengan adanya fitur Nagari Transfer ini, nasabah dapat melakukan transfer dengan kapanpun dan dimanapun dengan cepat.

4. Nagari Admin

Nagari admin merupakan salah satu fitur yang terdapat pada Nagari MBanking, fitur ini dapat digunakan untuk membantu nasabah memperoleh bukti atas transaksi yang telah dilakukan dan mengirim bukti tersebut kepada pihak lain sebagai bukti bahwa transaksi telah berhasil dilakukan, selain itu dalam fitur Nagari Admin ini, nasabah juga dapat melakukan penggantian PIN dan Kode Akses untuk menjaga keamanan akun Nagari M-Banking Nasabah dari penyalahgunaan pihak yang tidak bertanggung jawab. Dengan adanya fitur ini nasabah lebih merasa aman dalam menggunakan Nagari MBanking.

\section{Kendala Dalam Menggunakan Nagari M-Banking}

Setelah penulis melakukan wawancara kepada beberapa nasabah PT. Bank Pembangunan Daerah Sumatera Barat Cabang Siteba penulis mendapatkan bahwa banyaknya manfaat yang diperoleh oleh nasabah dengan adanya Nagari M-Banking ini, nasabah dapat mengakses Nagari M-Banking dengan mudah dalam meningkatkan mobalitas transaksi nasabah, namun juga nasabah juga memiliki kendala-kendala 
dalam meggunakan Nagari M-Banking, kandala ini dirasakan nasabah dan membuat nasabah enggan bertransaksi menggunakan Nagari M-Banking. Berikut ini kendalakendala yang dihadapi nasabah dalam menggunakan Nagari M-Banking sebagai berikut :

1. Masih rendahnya kemampuan nasabah dalam menggunakan M-Banking Kurangnya ilmu pengetahuan masyarakat tentang fasilitas M-Banking sehingga masih banyak yang tidak mengerti dalam penggunaan teknologi (Gaptek). Nasabah sering bertanya kepada customer service karena ketidakpahaman mereka dalam penggunaan aplikasi pada ponsel dalam melakukan transaksi melalui M-Banking sehingga para nasabah masih saja memilih bertransaksi dengan cara mendatangi kantor cabang atau ATM.

2. Butuh smartphone canggih untuk menggunakan M-Banking Agar Nagari M-Banking dapat digunakan, maka dibutuhkan perangkat atau smartphpone yang canggih. Banyaknya nasabah Bank Nagari di daerah terpencil, yang mana belum semua nasabah menggunakan smartphone, sehingga nasabah tidak bisa menggunakan M-Banking dan lebih memilih untuk datang langsung ke Bank Nagari atau ATM untuk bertransaksi.

3. Jaringan yang harus sesuai dengan provider yang terdaftar

Nasabah yang berada di daerah sulit untuk mengakses jaringan seperti di pedesaan, maka secara otomatis jaringannya akan terganggu. Hal tersebut yang menyebabkan nasabah pada Bank Nagari lebih memilih untuk tidak menggunakan aplikasi M-Banking yang mampu menghambat segala aktivitas bertransaksi dan dapat beresiko seperti cybercrime, selain itu ketika provider yang didaftarkan tidak memiliki paket data atau pulsa maka M-Banking tidak dapat diakses dengan menggunakan provider lain.

4. Kurang lengkap dan luasnya fitur yang tersedia

Masih terbatasnya fitur yang disediakan oleh Nagari M-Banking, seperti Mutasi Rekening, sehingga nasabah tidak dapat mengetahui dengan seksama dana yang masuk maupun keluar selama beberapa bulan terakhir dan Nagari M-Banking belum menyediakan fitur RDN yaitu fitur yang memungkinkan nasabah yang memiliki rekening pada perusahaan sekuritas untuk melakukan akses kepada rekening tersebut.

5. Tingkat keamanan yang belum sempurna

Banyak kasus penipuan atau cybercrime yang terjadi akibat penggunaan MBanking, jaringan M-banking yang terkoneksi langsung dengan internet, memudahkan para hacker untuk menduplikasi data nasabah, sehingga menggunakan data nasabah untuk keperluan pribadinya bahkan menguras habis dana yang ada di rekening nasabah, serta ketika perangkat atau smartphone nasabah yang di dalamnya terinstal aplikasi M-Banking hilang atau dicuri, maka semakin memudahkan para hacker atau pihak yang tidak bertanggung jawab dalam mengkases data nasabah. Belum adanya sistem keamanan yang berlapis memungkinkan kasus penipuan atau cybercrime akan terus terjadi. 
6. Dikenakan biaya tambahan

Ketika nasabah akan mendaftarkan rekening baru untuk keperluan transfer dana, maka nasabah akan dikenakan biaya SMS, hal ini akan dapat menyulitkan nasabah ketika nasabah hendak melakukan transefer dana segera tetapi tidak memiliki pulsa.

\section{SIMPULAN}

Berdasarkan pembahasan yang telah penulis lakukan pada bab sebelumnya mengenai penerapan M-banking dalam meningkatkan jasa dan pelayanan pada PT. Bank Pembangunan Daerah Sumater Barat Cabang Steba, maka penulis dapat menyimpulkan hal-hal sebagai berikut:

1. Secara umum PT. Bank Pembangunan Daerah Sumater Barat terus meningkatkan pelayanan bagi setiap nasabahnya agar nasabah terus aktif dan meningkatkan transaksi menggunakan Nagari M-Banking, dengan adanya aplikasi Nagari M-Banking ini mempermudah nasabah dalam melakukan transaksi, baik transaksi keuangan maupun transaksi non-keuangan.

2. Dengan adanya fitur Nagri $Q R$ mempermudah nasabah dalam melakukan pembayaran zakar, karena PT. Bank Pembangunan Daerah Sumater Barat. Bekerja sama dengan QRIS, sehingga pembayaran zakar dapat dilakukan dengan cepat dan mudah

3. Masih adanya hambatan atau kendala yang dihadapi oleh nasabah dalam menggunakan Nagari M-Banking seperti kurangnya kemampuan nasabah dalam menggunakan aplikasi dan masih banyaknya fitur yag kurang lengkap seperti mutasi rekening.

4. Penerapan Nagari M-Banking mempermudah nasabah dalam melakukan transaksi keuangan maupun non keuangan, sehingga nasabah tidak perlu datang langsung ke kantor bank atau bahkan ke ATM.

5. Masih rendahnya tingkat keamanan penggunaan Nagari M-Banking, karena aplikasi berhubungan langsung dengan internet, jadi sangat mudah untuk di hack dan ketika perangkat atau handphone nasabah hilang, data nasabah akan sangat riskan untuk digandakan.

6. Penggunaan Nagari M-banking harus menuntut nasabah menggunakan perangkat atau handphone yang canggih dan memiliki akses internet, sehingga nasabah yang berada di daerah pelosok yang tidak memiliki handphone yang canggih serta internet yang cepat, tidak bisa menggunakan Nagari M-Banking.

\section{DAFTAR PUSTAKA}

Beti Andriani, R. S. (2019). Pengawasan Kredit Pt. Bank Perkreditan Rakyat (Bpr) Ophir Pasaman Barat, 1-12. https://doi.org/10.31219/osf.io/aunvc

Farida Jasfar. (2014). Manajemen Jasa Terpadu. Jakarta: Ghalia Indonesia

Fernandes, Y. D., \& Marlius, D. (2018). Peranan Customer Service Dalam Meningkatkan Pelayanan Kepada Nasabah Pada PT. Bank Pembangunan Daerah 
Sumatera Barat Cabang Utama Padang. https://doi.org/10.31227/osf.io/wrh3p Hidayati, R. R., \& Marlius, D. (2018). Aktivitas Promosi Dalam Meningkatkan Dana Pihak Ketiga Pada PT. Bank Perkreditan Rakyat (BPR) Batang Kapas Pesisir Selatan. https://doi.org/10.31227/osf.io/8dgqn

Indah Dewi. (2016). Pengaruh E-Banking dan Kualitas Pelayanan terhadap Loyalitas Nasabah pada PT. Bank BNI'46 Cabang Langsa. Falkutas Ekonomi. Universitas Samudera

Kasmir. (2010). Dasar-Dasar Perbankan. Jakarta:Kencana

Laman www.kompas.com. Diakses tanggal 23 Maret 2020

Marlius, D., \& Nurfazila, N. (2020). Aktivitas Pemasaran Tabungan Pada Pt. Bank Pembangunan Daerah Sumatera Barat Cabang Pembantu Tarusan. https://doi.org/10.31219/osf.io/fvqc7

Marlius, D. (2018). Loyalitas Nasabah Bank Nagari Syariah Cabang Bukittinggi Dilihat Dari Kualitas Pelayanan. Jurnal Pundi. Volume 1. No. 3. Hal.12-22. https://doi.org/10.31575/jp.v1i3.60

Marlius, D. (2018). Pengaruh Dimensi Kualitas Pelayanan Website Akademik Terhadap Kepuasan Mahasiswa Pada STIE "KBP". Jurnal Ipteks Terapan. Volume 12. No. 2. Hal. 116-128. http://doi.org/10.22216/jit.2018.v12i2.633

M. Nur Nasution. (2016). Majemen Perbankan Perbasis Teori dan Praktek. Jakarta: Salemba Empat

Riswandi. (2015). Buku Pintar Perbankan. Yogyakarta: ANDI

Safitri, R. N., \& Marlius, D. (2017). Penerapan E-Banking Dalam Meningkatkan Jasa Dan Layanan Perbankan Di PT. Bank Rakyat Indonesia Cabang Padang. https://doi.org/10.31227/osf.io/gkv8t

Wina Lestari. (2017). Pengaruh E-Banking dan Kualitas Pelayanan Terhadap Loyalitas Nasabah Pada PT. Bank Mualamat Tbk SM Raja Medan. Falkutas Ekonomi dan Bisnis Islam. Universitas Islam Negeri Sumatera Utara 